UNIVERSUM • Vol. $30 \bullet$ No $2 \cdot 2015 \bullet$ Universidad de Talca

\footnotetext{
The case of the conditionals with disjunctions embedded into their antecedents. Mental logic versus semantic models Miguel López Astorga

Pp. 143 a 152
}

\title{
THE CASE OF THE CONDITIONALS WITH DISJUNCTIONS EMBEDDED INTO THEIR ANTECEDENTS. MENTAL LOGIC VERSUS SEMANTIC MODELS ${ }^{1}$
}

\author{
El caso de los condicionales con disyunciones incluidas en sus antecedentes. \\ Lógica mental versus modelos semánticos
}

\author{
Miguel López Astorga*
}

\begin{abstract}
The mental models theory and the mental logic theory are two alternative theories trying to explain, describe, and predict human reasoning. Both of them are consistent with most the experimental results reported in cognitive science literature. Therefore, it is hard to decide which is the correct one. In this paper, I argue that the predictions of both theories concerning the conditionals with disjunctions embedded into their antecedents are different, and that certain results that can be found in the literature seems to support the predictions of the mental logic theory about this kind of conditionals.
\end{abstract}

Keywords: Conditional, disjunction, formal rules, mental logic, mental models.

\footnotetext{
${ }^{1}$ This paper is a result of the Project No I003011, "Algoritmos adaptativos e inferencias lógicas con enunciados condicionales", supported by the Directorate for Research of Talca University (Dirección de Investigación de la Universidad de Talca), Chile. The author, who is also the main researcher of that Project, would like to thank the mentioned institutions for their help in funding this paper.

* Institute of Humanistic Studies "Juan Ignacio Molina", Talca University. Talca, Chile. E-mail address:milopez@utalca.cl
}

Received November, 27, 2014. Accepted March, 11, 2015. 


\section{RESUMEN}

La teoría de los modelos mentales y la teoría de la lógica mental son dos teorías alternativas que tratan de explicar, describir y predecir el razonamiento humano. Ambas son consistentes con la mayor parte de los resultados experimentales presentados en la literatura de la ciencia cognitiva. Por tanto, es complejo decidir cuál es la correcta. En este trabajo, argumento que las predicciones de las dos teorías con respecto a los condicionales con disyunciones incluidas en sus antecedentes son diferentes y que ciertos resultados que se pueden encontrar en la literatura parecen apoyar las predicciones de la teoría de la lógica mental acerca de este tipo de condicionales.

Palabras clave: Condicional, disyunción, reglas formales, lógica mental, modelos mentales.

\section{INTRODUCTION}

At present, there are several theories about human reasoning. In this paper, I will address two of them that have a great explicative and predictive scope: the mental models theory (from now on, M-Mt) and the mental logic theory (from now on, M-Lt). The approach of M-Mt (e.g., Byrne \& Johnson-Laird, 2009; Johnson-Laird, 2010, 2012; Johnson-Laird, Byrne, \& Girotto, 2009; Khemlani \& Johnson-Laird, 2009; Khemlani, Orenes, \& Johnson-Laird, 2012, 2014; Orenes \& Johnson-Laird, 2012) is semantic. According to this theory, people do not make inferences applying formal rules, but thinking about the combinations of possibilities that can be attributed to the propositions. On the other hand, M-Lt (e.g., Braine \& O’Brien, 1998a; O’Brien, 2009; O’Brien \& Manfrinati, 2010) proposes a syntactic framework. Following $\mathrm{M}-\mathrm{Lt}$, people reason using formal rules or schemata. However, as far as this last theory is concerned, it is important to highlight that it is not equivalent to classical propositional calculus or systems such as that of Gentzen (1934). Likewise, M-Lt is different to other syntactic approaches to human reasoning (e.g., Rips, 1994, 2011). M-Lt only accepts the rules of standard propositional calculus that are compatible with experimental results. Besides, all the rules do not have the same status in M-Lt. There are several types of rules ('Core Schemata', 'Feeder Schemata', 'Incompatibility Schemata'...). In my view, this distinction between M-Lt and other syntactic proposals or systems needs to be evinced because M-Lt is often misunderstood and considered to be equivalent to other approaches or calculi.

It is really difficult to find proofs or facts that reveal which of these two theories (M-Mt and M-Lt) is the theory that can better explain and predict the human cognitive phenomena. However, I think that there are certain conditional 
inferences that can show this and that the results of experiments using such inferences can prove that M-Lt is a better option. Those inferences correspond to a version of Chrysippus' Modus Ponens in which the antecedent of the conditional is not a propositional variable, but different propositional variables linked by means of disjunctions. The inferences of this kind are important because, as I will explain below, the predictions of M-Mt and M-Lt concerning them are different and, as indicated, the experimental results seem to support those of M-Lt. The fact is that, according to $\mathrm{M}-\mathrm{Mt}$, it can be said that such versions should be more difficult to solve than the inferences based on the original structure of Modus Ponens. On the other hand, M-Lt holds that both the versions with disjunctions embedded into the antecedent of the conditional and the original versions correspond to Core Schemata that people use whenever they can do it and that none of the two inferences is harder that the other one. The key is that, as mentioned, the results offered by the literature -in particular, some experiments carried out by some proponents of M-Lt- appear to demonstrate that, indeed, individuals use the formal rules of M-Lt.

My aim in this paper is to prove this last idea and to argue in favor of it. To do so, I will start by commenting the account of M-Mt on conditionals and disjunctions. Then I will expose how the mentioned inferences are considered by M-Lt and why this theory thinks that both of them are equivalent in difficulty level. Finally, I will indicate which the exact predictions of M-Mt concerning the inferences are and why those predictions are inconsistent with certain experimental results of cognitive science literature.

\section{M-MT, DISJUNCTIONS, AND CONDITIONALS}

As said, M-Mt claims that people reason by considering the combinations of possibilities of propositions. In particular, as far as conditionals and disjunctions are concerned, the possibilities or 'mental models' that this theory proposes are -as indicated, for example, in Johnson-Laird (2012)- the following:

Conditional (if $\mathrm{p}$ then $\mathrm{q}$ ):

$\mathrm{p} / \mathrm{q}$

Disjunction ( $\mathrm{p}$ or $\mathrm{q})$ :

$\mathrm{p} / \mathrm{q}$

$\mathrm{p}$

q 
This means that this theory states that, in principle, people tend to pay attention to only a combination of possibilities when they are thinking about a conditional, and that that combination is $\mathrm{p}$ and $\mathrm{q}$. In the case of disjunction, which will be considered in this paper as inclusive, the initial combinations are, as shown, three: $\mathrm{p}$ and $\mathrm{q}, \mathrm{p}$ alone, and $\mathrm{q}$ alone.

However, when individuals' processing effort is greater, they can detect the 'fully explicit models', i.e., all the possibilities that truly can be attributed to a proposition. The fully explicit models of conditional are -according to works supporting M-Mt such as Johnson-Laird (2012) - as follows:

$\mathrm{p} / \mathrm{q}$

$\neg \mathrm{p} / \mathrm{q}$

$\neg \mathrm{p} / \neg \mathrm{q}$

Where ' $\neg$ ' stands for denial.

The missing combination (i.e., $p$ and $\neg q$ ) cannot be accepted because, when the antecedent of a conditional is true, its consequent cannot be false.

Likewise, the fully explicit models that, following M-Mt, can be linked to disjunction are these ones:

$\mathrm{p} / \mathrm{q}$

$\mathrm{p} / \neg \mathrm{q}$

$\neg \mathrm{p} / \mathrm{q}$

The difference between the mental models and the fully explicit models of disjunctions is that, as it can be checked in the second ( $p$ and $\neg q$ ) and the third ( $\neg p$ and q) models, the denials are made explicit.

Given that both conditional and disjunction are present in the version of Modus Ponens indicated above, the predictions of M-Mt on that kind of inference are obvious. Nevertheless, before analyzing such predictions, it can be opportune to describe them in more details and to explain why they are so important and relevant in M-Lt.

\section{M-LT AND THE TWO VERSIONS OF MODUS PONENS}

As it is well known, the original version of Modus Ponens has this formal structure: 
$\mathrm{x} \rightarrow \mathrm{y}, \mathrm{x} / /$ Ergo y

Where ' $\rightarrow$ ' means conditional relation.

As said, this is a very relevant rule in M-Lt. It is a Core Schema, i.e., as also indicated, a schema that individuals apply whenever possible. In particular it is the schema 7 in Braine and O’Brien (1998b) and, for this reason, from now on, I will refer to it as 'S7'.

But the version with disjunctions embedded into the antecedent of the conditional is very important for M-Lt too. Its formal structure is this one:

$\left(\mathrm{x}_{1} \mathrm{v} \ldots \mathrm{v \textrm {x } _ { \mathrm { n } }}\right) \rightarrow \mathrm{y}, \mathrm{x}_{\mathrm{i}} / /$ Ergo $\mathrm{y}$

This schema is a Core Schema of M-Lt as well. In particular it is the schema 2 in Braine and O'Brien (1998b). For this reason, I will call it 'S2' in the next pages.

Thus, the most important point here is that, as mentioned, both S7 and S2 are Core Schemata of M-Lt and that, therefore, they are generally used by people in an automatic and routine way. This in turn means that, according to M-Lt, neither S7 nor S2 are hard to apply. In fact the proponents of M-Lt tried to prove this last idea by means of empirical experiments and their results seemed to confirm that, certainly, they are very ease schemata that people constantly use without any special difficulty. A curious datum in this regard was, nonetheless, that it was found that, despite the fact that the structure of S2 appears to be more complicated, it is easier to apply than S7. This is because, although the differences were not very great, the participants made more mistakes when they had to apply S7 than when they had to apply S2. Indeed, the percentage of errors of S2 found in the experiments was $0 \%$ and that of $S 7$ was $2 \%$ (see Braine \& O'Brien, 1998b, and Braine, Reiser, \& Rumain, 1998). This reveals that, as said, although the difference is not very relevant, if one of these two schemata is more difficult, that schema is S7.

These results are really interesting if the goal of this paper is taken into account. As I understand it, from the theses of M-Mt explained in the previous section, it can be drawn the conclusion that, according to this last theory, S2 is harder to $S 7$ and that, for this reason, the percentage of errors of $S 2$ would have to be higher. I will argue this idea in the next section. 


\section{M-MT, S2, AND S7}

The framework of M-Mt implies that the inferences that refer to more models are more difficult that those that need less models. If this thesis is correct, form the perspective of M-Mt, S2 should be harder than S7. I will show why.

Firstly, I will take only the mental models into account. The inferential process in the case of S7 would be as follows:

The mental model of the first premise would be:

$\mathrm{x} / \mathrm{y}$

The second premise states that $\mathrm{x}$ is true. Therefore, it is only possible that $\mathrm{y}$ is true too, since no other combination is considered.

Nevertheless, if $\mathrm{n}=2$, the mental models of the first premise of S2 would be the following:

$\mathrm{x}_{1} / \mathrm{x}_{2} / \mathrm{y}$

$x_{1} / y$

$\mathrm{x}_{2} / \mathrm{y}$

Regardless of what the second premise indicated $\left(\mathrm{x}_{1}\right.$ or $\left.\mathrm{x}_{2}\right)$, it is evident that, to conclude $\mathrm{q}$, individuals must pay attention to the previous three models. So, based on M-Mt, the prediction would be that, even in the case that $n=2, S 2$ is more difficult than S7, which, as mentioned, is incompatible with the results presented by Braine and O’Brien (1998b) and Braine et al. (1998).

But, if we imagine a situation in which the participants consider all the fully explicit models, the prediction of M-Mt does not change. For S7, the models would be these ones:

$$
\begin{aligned}
& \mathrm{x} / \mathrm{y} \\
& \neg \mathrm{x} / \mathrm{y} \\
& \neg \mathrm{x} / \neg \mathrm{y}
\end{aligned}
$$

By stating $\mathrm{x}$, the second premise eliminates the last two models and $\mathrm{y}$ is concluded. Nonetheless, being $\mathrm{n}=2$, the first premise of S2 needs more models:

$$
\begin{aligned}
& \mathrm{x}_{1} / \mathrm{x}_{2} / \mathrm{y} \\
& \mathrm{x}_{1} / \neg \mathrm{x}_{2} / \mathrm{y}
\end{aligned}
$$


$\neg \mathrm{x}_{1} / \mathrm{x}_{2} / \mathrm{y}$

$\neg \mathrm{x}_{1} / \neg \mathrm{x}_{2} / \mathrm{y}$

$\neg \mathrm{x}_{1} / \neg \mathrm{x}_{2} / \neg \mathrm{y}$

In the models fourth and fifth, $\neg \mathrm{x}_{1}$ and $\neg \mathrm{x}_{2}$ correspond to the denial of the antecedent, i.e., to $\neg\left(\mathrm{x}_{1} \vee \mathrm{x}_{2}\right)$. Intuitively, it can be thought that only one model corresponds to $\neg\left(\mathrm{x}_{1} \mathrm{v}_{2}\right): \neg \mathrm{x}_{1}$ and $\neg \mathrm{x}_{2}$. In any case, in papers such as Khemlani et al. (2012, 2014), explicit arguments on this issue can be found. Khemlani et al.'s (2012, 2014) proposal is an extension of M-Mt in order to describe the models that, according to this theory, correspond to denied propositions. Given that the general thesis is that the models of a denied expression are the complement of the models of that expression without denial, and that the models of $\mathrm{x}_{1} \mathrm{vx_{2 }}$ are $\mathrm{x}_{1}$ and $\mathrm{x}_{2}, \mathrm{x}_{1}$ and $\neg \mathrm{x}_{2}$, and $\neg \mathrm{x}_{1}$ and $\mathrm{x}_{2}$, the only model of $\neg\left(x_{1} v x_{2}\right)$ is $\neg x_{1}$ and $\neg x_{2}$, i.e., the complement of $x_{1} v x_{2}$.

However, what is important here is that S7 requires three fully explicit models and that S2 refers to five fully explicit models. The prediction of M-Mt hence continues to be inconsistent with the mentioned experimental results.

Furthermore, the fact that the prediction of M-Mt is not adequate can be seem more clearly if it is supposed a scenario in which $n=3$. In such a scenario, the mental models of the first premise of S2 would be four:

$\mathrm{x}_{1} / \mathrm{x}_{2} / \mathrm{x}_{3} / \mathrm{y}$

$\mathrm{x}_{1} / \mathrm{y}$

$\mathrm{x}_{2} / \mathrm{y}$

$\mathrm{x}_{3} / \mathrm{y}$

Therefore, if the thesis of M-Mt were correct, S2 would be four times more difficult than S7 (remember that the mental model of the first premise of $\mathrm{S7}$ is just one). Worse still is the situation in which $\mathrm{n}=3$ and individuals take the fully explicit models into account, because, in that situation, the combinations corresponding to the conditional premise of S2 would be nine:

$\mathrm{x}_{1} / \mathrm{x}_{2} / \mathrm{x}_{3} / \mathrm{y}$

$\mathrm{x}_{1} / \neg \mathrm{x}_{2} / \mathrm{x}_{3} / \mathrm{y}$

$\mathrm{x}_{1} / \mathrm{x}_{2} / \neg \mathrm{x}_{3} / \mathrm{y}$

$\neg \mathrm{x}_{1} / \mathrm{x}_{2} / \mathrm{x}_{3} / \mathrm{y}$

$\mathrm{x}_{1} / \neg \mathrm{x}_{2} / \neg \mathrm{x}_{3} / \mathrm{y}$

$\neg \mathrm{x}_{1} / \neg \mathrm{x}_{2} / \mathrm{x}_{3} / \mathrm{y}$

$\neg \mathrm{x}_{1} / \mathrm{x}_{2} / \neg \mathrm{x}_{3} / \mathrm{y}$

$\neg \mathrm{x}_{1} / \neg \mathrm{x}_{2} / \neg \mathrm{x}_{3} / \mathrm{y}$

$\neg \mathrm{x}_{1} / \neg \mathrm{x}_{2} / \neg \mathrm{x}_{3} / \neg \mathrm{y}$ 
Because the fully explicit models of the first premise of S7 are three, the difference is evident and leads one to think that, if $\mathrm{n}$ has a high value, the prediction of M-Mt is not simply that S2 is harder, but that it is unfeasible. Therefore, it can be said that the experimental results obtained by the proponents of M-Lt seem to be compatible only with their theory, i.e., with the idea that both S2 and S7 are Core Schemata that people use whenever possible.

\section{CONCLUSIONS}

The idea that different cognitive theories can account for a same experimental result is not new (see, for example, López-Astorga, 2013a, 2013b, 2013c, 2014). For this reason, it is always important to identify aspects, scenarios, or situations in which the predictions of the different theories are not the same, since such aspects, scenarios, or situations can show which theory is more appropriate. As mentioned, both M-Mt and M-Lt can describe and predict most cognitive phenomena, but I think that I have shown in this paper a particular case in which the predictions of those two theories are clearly different. As I have also explained, certain experimental results seem to support the prediction of M-Lt. However, because this paper has only addressed a very particular kind of inference, maybe further research regarding this issue is needed.

In any case, there are some points that it is always necessary to remember. It is absolutely true that many experimental results reported by the literature cannot be explained by calculi such as standard propositional calculus or frameworks such as that of Rips (1994, 2011). Nevertheless, the mental logic proposed by M-Lt is not similar to such calculi and frameworks. In fact, it is very different because it only admits the rules or schemata that, according to empirical studies, people really use. This point is especially relevant because, in many occasions, when it is proved that a certain experimental result is inconsistent with a particular syntactic approach, it can be observed a trend to extrapolate the conclusions and to consider all the syntactic approaches (including, of course, M-Lt) to be incorrect.

But another point that is important is the idea that M-Lt does not require exclusivity (O'Brien, 1998). This means that maybe the problem studied in this paper does not only refer to two options: to accept M-Mt or to assume M-Lt. Perhaps a third option is possible and human mind can resort, depending on the circumstances, both to semantic models and to syntactic rules. Theses akin to this one have also been suggested in other papers (e.g., in López-Astorga, 2014a) and such theses can be the framework that leads future research. 
The case of the conditionals with disjunctions embedded into their antecedents. Mental logic versus semantic models

\section{REFERENCIAS}

Braine, Martin D. S. \& O’Brien, David P. (Eds.). Mental Logic. Mahwah: Lawrence Erlbaum Associates, Inc., Publishers, 1998a.

Braine, Martin D. S. \& O’Brien, David P. “The theory of mental-propositional logic: Description and illustration.” In Martin D. S. Braine \& David P. O’Brien (Eds.). Mental Logic. Mahwah: Lawrence Erlbaum Associates, Inc., Publishers, (1998b): 79-89.

Braine, Martin D. S., Reiser, Brian J., \& Rumain, Barbara. "Evidence for the theory: Predicting the difficulty of propositional logic inference problems." In Martin D. S. Braine \& David P. O’Brien (Eds.). Mental Logic. Mahwah: Lawrence Erlbaum Associates, Inc., Publishers, (1998): 91-144.

Byrne, Ruth M. J. \& Johnson-Laird, Philip N. “'If' and the problems of conditional reasoning", Trends in Cognitive Science 13/7 (2009): 282-287.

Gentzen, Gerhard. "Untersuchungen über das logische I", Mathematische Zietschrift 39 (1934): 176-210.

Johnson-Laird, Philip N. "Against logical form", Psychologica Belgica 5/3\&4 (2010): 193-221.

Johnson-Laird, Philip N. "Inference with mental models." In Keith J. Holyoak \& Robert G. Morrison. The Oxford Handbook of Thinking and Reasoning. New York: Oxford University Press, (2012): 134-145.

Johnson-Laird, Philip N., Byrne, Ruth M. J., \& Girotto, Vittorio. “The mental models theory of conditionals: A reply to Guy Politzer”, Topoi 28 (2009): 78-80.

Khemlani, Sangeet \& Johnson-Laird, Philip N. "Disjunctive illusory inferences and how to eliminate them", Memory \& Cognition 37/5 (2009): 615-623.

Khemlani, Sangeet, Orenes, Isabel, \& Johnson-Laird, Philip N. "Negations: A theory of its meaning, representation, and use", Journal of Cognitive Psychology 24/5 (2012): 541-559.

Khemlani, Sangeet, Orenes, Isabel, \& Johnson-Laird, Philip N. "The negation of conjunctions, conditionals, and disjunctions", Acta Psychologica 151 (2014): 1-7. 
López-Astorga, Miguel. "Are conditional and disjunction really comparable?", Universum 28/2 (2013a): 229-242.

López-Astorga, Miguel. "Alcoholism and conditional reasoning: Difficulties in specific mental domains or in general use of heuristics?", Psychologica Belgica 53/4 (2013b): 3-16.

López-Astorga, Miguel. "Anxiety, confirmation bias, and selection task: Possible explanations", Cogency 5/2 (2013c): 77-91.

López-Astorga, Miguel. "Mental models and syntactic rules: A study of the relations between semantics and syntax in inferential processes", Analele Universitatii din Craiova, Seria Filosofie 33/1 (2014): 107-117.

O’Brien, David P. "Mental logic and irrationality. We can put a man on the moon so why can't we solve those logical reasoning problems?” In Martin D. S Braine \& David P. O’Brien (Eds.). Mental Logic. Mahwah: Lawrence Erlbaum Associates, Inc., Publishers, (1998): 23-43.

O’Brien, David P. "Human reasoning includes a mental logic", Behavioral and Brain Sciences 32 (2009): 96-97.

O’Brien, David P. \& Manfrinati, Andrea. "The mental logic theory of conditional proposition.” In Mike Oaksford \& Nick Chater (Eds.). Cognition and Conditionals: Probability and Logic in Human Thinking. Oxford: Oxford University Press, (2010): 39-54.

Orenes, Isabel \& Johnson-Laird, Philip N. "Logic, models, and paradoxical inferences”, Mind \& Language 27/4 (2012): 357-377.

Rips, Lance J. The Psychology of Proof: Deductive Reasoning in Human Thinking. Cambridge: Massachusetts Institute of Technology (MIT) Press, 1994.

Rips, Lance J. Lines of Thought: Central Concepts in Cognitive Psychology. New York: Oxford University Press, 2011. 